Einzelnen überlassen werden, bis sich die Arbeitsgruppen auf ein Vorgehen einigen konnten.

Mit einfachen Methoden, z. B. durch Addition von 4 möglichen Risikofaktoren beim IMWG-Score (Alter, IADL, ADL und Komorbiditätsindex) oder dem R-MCI mit seinen 6

\section{"Personalisierte Medizin in jedem Sinne des Wortes sollte unser Ziel für ältere Myelompatienten sein.}

Parametern, kann das "klinische Bauchgefühl" des behandelnden Arztes hinsichtlich der Therapiefähigkeit eines Patienten deutlich präzisiert werden. Die Hazard Ratios für die Gruppe der „frail", also anfälligen oder geschwächten, Patienten reichen bezüglich des Gesamtüberlebens von 6,0 (IMWG) bis 8,3 (R-MCl). Eine besondere Stärke im Hinblick auf die Risikoabschät- zung für das progressionsfreie Überleben ist beim R-MCl zu sehen, da dieser die Zytogenetik berücksichtigt. Sämtliche Parameter liegen in der Regel vor, da sie entweder zum diagnostischen (Komorbiditäten, Zytogenetik) oder Pflege-Standard gehören (ADL/IADL).

Wie wohltuend ist dieser Bericht in Anbetracht der Tatsache, dass "personalisierte Medizin" in aller Munde ist und in seltenen Fällen die Person hinsichtlich ihrer physischen und psychischen Reserven im Fokus steht. Es ist der besondere Verdienst der Arbeitsgruppe um Monika Engelhardt, immer wieder das Individuum im Zusammenhang mit seiner Erkrankung und deren spezifischer Risiko-Klassifizierung (z.B. molekularer, histo-morphologischer oder laborchemischer Art) zur Diskussionsgrundlage für TherapieOptimierungen zu machen.

Die Darstellung und Validierung der grundlegenden prognostischen Aussagekraft dieser Parameter ist ein wichtiger Schritt, um beispielsweise in Zukunft auch deren prädiktive Aussagekraft erörtern zu können.

Es bleibt zu hoffen, dass die weiteren geplanten prospektiv, anhand von Assessment-Ergebnissen stratifizierten Therapiestudien - womöglich sogar mit eben den genannten Risikofaktoren „Erhalt der Leistungsfähigkeit" oder auch "Lebensqualität" als Zielparameter - uns helfen, dem älteren Myelompatienten personalisierte Therapie in jedem Sinne des Wortes anbieten zu können.

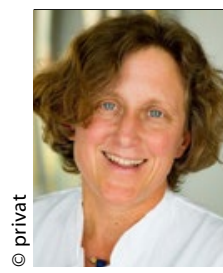

Dr. med. Barbara Deschler-Baier Comprehensive Cancer Center Mainfranken Universitätsklinikum Würzburg Deschler_B@ukw.de

\title{
Multiples Myelom: Serum-FLC- schlägt Urinanalyse
}

\section{Um das Therapieansprechen von Patienten mit Leichtketten-Myelom zu beurteilen, empfehlen französi- sche Onkologen die Messung der freien Leichtketten (FLC) im Serum als Methode der Wahl.}

$\mathrm{M}$ it Konzentrationen von FLC im Serum (sFLC) gelingt ein sensitiverer Nachweis des Leichtketten-Myeloms (LCMM) als mit der Bestimmung des monoklonalen Proteins im Urin; das ist in vielen Vergleichsstudien gezeigt worden. Jetzt haben Ärzte erstmals Belege, dass auch das Therapieansprechen und die Prognose durch sFLC-Messungen besser abgebildet werden.

Die Mediziner um Thomas Dejoie plädieren deswegen dafür, bei LCMM-Patienten zur Verlaufskontrolle von Anfang an auf sFLC zu setzen - und nicht erst dann, wenn das monoklonale Protein im Urin oder im Serum unter die Nachweisgrenze gefallen ist.

Dejoie und Kollegen haben bei 113 LCMM-Patienten, die an einer randomisierten Therapiestudie teilgenommen hatten, die Aussagekraft von Serumbestimmungen der involvierten (= tumor- assoziierten) Leichtkette (iFLC) mit der Urinprotein-Elektrophorese (UPEP) verglichen. Initial hatten $100 \%$ der Patienten ein abnormes Serum-iFLC, aber nur $78 \%$ ein positives UPEP-Ergebnis; eine messbare Erkrankung hatten $100 \%$ (iFLC $\geq 100 \mathrm{mg} / \mathrm{l}$ ) versus $64 \%$ (UPEP $\geq 200 \mathrm{mg} / 24 \mathrm{~h}$ ). Nach dem 1 . und dem 3 . Therapiezyklus blieb der iFLC-Wert bei $71 \%$ und $46 \%$ der Patienten erhöht, die UPEP war noch bei $37 \%$ und $18 \%$ positiv. Alle Patienten mit nach der 3. Runde positiver UPEP hatten auch erhöhte iFLC-Spiegel.

Dass die Serum-FLC-Messungen tatsächlich die Krankheit besser widerspiegelten (und auf Basis der Urinmessungen das Therapieansprechen überschätzt wurde), zeigte sich beim progressionsfreien Überleben (PFS): Patienten, die nach dem dritten Zyklus einen erhöhten iFLC-Wert oder ein abnormes Verhältnis von Kappa- zu Lamda-Leichtketten im Serum aufwiesen, hatten ein signifikant kürzeres PFS als Patienten mit unauffälligen Werten. Die Befunde bei UPEP oder Immunfixation im Urin standen dagegen nicht in Beziehung zum PFS.
Wurden die 82 Patienten mit negativer UPEP anhand ihrer iFLC-Werte in eine Gruppe mit erhöhten und eine Gruppe mit normalen Werten aufgeteilt, hatten abermals diejenigen mit höheren Werten ein kürzeres PFS.

Auch das Erreichen von MRD(„minimal residual disease“)-Negativität nach der Konsolidierungstherapie ließ sich mit dem Serum-FLC-Verhältnis sehr gut vorhersagen: Eine Normalisierung schon während der Induktionstherapie hatte einen positiven Vorhersagewert (PPV) von $100 \%$. Dagegen betrug der PPV einer negativen Urin-Immunfixation nach dem 1. bzw. 3. Therapiezyklus nur 81 bzw. $78 \%$.

Fazit: Bei Patienten mit einem Leichtketten-Myelom hat die Messung von FLC im Serum nicht nur praktische Vorteile gegenüber der Urinanalyse: Die Serumanalyse ist auch sensitiver und ermöglicht eine bessere Prognose des Krankheitsverlaufs. Beate Schumacher

Dejoie T et al. Serum Free Light Chains Should be the Target of Response Evaluation in Light Chain Multiple Myeloma Rather than Urines. Blood. 2016;128(25):2941-8. 